\title{
Conflicting Ideologies in Three Magical Realist Children's Novels by Isabel Allende
}

\author{
Yvonne Hammer
}

A recent movement to establish ecopoetic frames in children's literature has led to the exploration of a critical confluence of magical realism with ecocriticism. Because of a common capacity to interrogate dominant Western value systems, magical realist discourse has been linked with ecopoetic frames that promote narrative representations of environmental justice movements. Such an alignment is possible because the postcolonial heritage of magical realism, founded by Latin American authors, offers a site of resistance by which the dominant ideologies of colonising nations are interrogated. In fictions which form the basis for ecocriticism authors may create similar narrative spaces of resistance to encode representations of ecological malpractice which are enacted upon indigenous peoples by an invasive non-indigenous presence. This ideological confluence between magical realist strategies and ecocritical frames represents a problematic interface between indigenous and non-indigenous subjectivities because representations of ecological intervention are primarily Western in origin, while magical realism promotes representations of indigenous voice. The problems that arise from this alignment are particularly evident in Allende's three quest fictions for children in that the two dominant eco-warrior protagonists are nonindigenous and narrative perspective is largely derived from Western subject focalisations. The author's magical realist frame by which Western cultural positions are interrogated has thus been compromised by the fact that subject focalisations privilege non-indigenous perceptions about the plight of tribal peoples in a manner that limits indigenous voice. Even though each eco-warrior quest instigates magical realist strategies - irreducible elements of magic, phenomenological elements, merged frames that anchor magical elements in mimetic detail (Faris, 2004)the authorial intent to expose exploitation of indigenous peoples is framed by Western ecocritical perspectives. Furthermore, because representations of magical power saturate depictions of eco-warrior agency, the grounding mimetic is disrupted and quest resolutions are imbued by fantasy.

Thus, even as Allende's magical realist fictions set out to represent marginal and indigenous perspectives - a function attributed to magical realism by, for example,
Faris (2004, p.133) and D'haen (1995, p.191) - her ecowarrior subjects construct non-indigenous representations of marginalised perspectives. Bradford identifies this capacity for non-indigenous authors to represent indigenous focalising agents as highly complex, involving the capacity to 'imagine how characters think, value, and feel' (2007, p.73). Allende's creation of non-indigenous eco-warrior protagonists, however well constructed, replicates what Bradford has described as representation 'from the outside [...] from the perspective of majority cultures' (2007,p.73). Protagonists are situated as observers and subsequently articulate environmental justice issues from an external frame of understanding.

The convergent aims of dual interrogative frames - ecocriticism and magical realism - also provide contradictory grounds for the representation of marginal positions because indigenous perspectives are represented through the lens of non-indigenous agents. Problematic representations then occur when a non-indigenous external perspective also encodes the ideological frame of Western culture through quest structures that are imbued with cultural traditions. Consequentially, a dominant Western quest structure, which depicts the coming of age enlightenment of eco-warrior protagonists, subverts the author's interrogation of Western epistemological frames and disrupts the magical realist mode which privileges subaltern perspectives. Quest frames focus the text upon rescue rather than the promotion of indigenous agency encoding eco-warrior action: the intention to promote the rights of indigenous tribes, the deliverance of indigenous people from evil forces, and the continuation of valiant adventures. Because eco-warrior quests fail to deliver voice and agency to marginalised tribes, there is a surprising silence in Allende's novels in that indigenous subjects are, for the most part, depicted as helpless victims of change.

Western perspectives and practices are interrogated in ways that advocate the human rights of indigenous cultures in Allende's three quest fictions: City of the Beasts (2002), Kingdom of the Golden Dragon (2004), and Forest of the Pygmies (2005). Nevertheless, because the author represents the interrogative observations through a nonindigenous lens this site of resistance emerges from within the frame of a Western perspective and remains an external 
viewpoint. The first novel in the series, City of the Beasts, examines the plight of Amazonian tribes: tribal lands are threatened by mining ventures, and tribal people are targeted for extinction because a devious plan to introduce illness by inoculation with measles virus has been instigated by a trusted medical practitioner. The second quest, Kingdom of the Golden Dragon, is set in a hidden Himalayan land where a deeply spiritual and peaceful nation - The Forbidden Kingdom - is threatened by external forces: the collector, a powerful Westerner, desires the kingdom's powerful artefact, the famed golden dragon. The death of the King compels the young prince, Dil Bahadur, to negotiate his initiation and lead the kingdom through a time of change. Forest of the Pygmies, set in the swampy forests of Kenya, begins with a search for missing Western missionaries and unveils the plight of a pygmy tribe, dominated by corrupt officials, enslaved by a powerful district commander, and blackmailed into a life of illegal poaching. In each novel, Allende's protagonists, Alexander and Nadia, are ecowarriors who engage in a spiritual and physical battle for environmental justice and protection of indigenous peoples and their rights. The magical abilities of Alexander and Nadia also prove the grounds for agential behaviours and undergird their interventions by ensuring the success of each quest.

Allende employs a magical realist mode to expose differing perceptions of reality but this interrogation of narrative point of view is limited by minimal representations of indigenous perceptions. As a result, the narrative focalizations, which encode alternative interpretations of phenomena, also accentuate the encultured assumptions of the quest narrative, a Western tradition that has an interpretive function. So although each of Allende's novels contests the assumed superiority of both perceptions and perspectives that inform Western views, because her ecowarrior protagonists are non-indigenous the eco-political event frames that align exploitation of indigenous tribes with environmental abuse represent an external perspective. Whilst magical realist discourse 'undermines the right to represent the world' (Faris 2004, p.133), the representation of an eco-warrior frame appropriates discursive space from this emergent subaltern voice re-asserts the right of a dominant culture to speak for indigenous peoples and establishes indigenous silence.

Representations of childhood agency and voice are strongly supported by the eco-warrior protagonists who act as catalysts for environmental justice and indigenous rights. But despite Allende's overt intent to promote environmental justice rights, the strength of her ecowarrior representation has an unfortunate corollary when indigenous representations of efficacy are understated. What Bradford examines as the problematic appropriation of the traditional quest structure in representation of indigenous subjectivity may be defined as the cause of this destabilisation in Allende's magical realist and ecocritical frame. Bradford goes further in reflecting that the Universalist assumptions of Joseph Campbell's (1949) theory of the 'monomyth' result in a reinstatement of 'power relations that privilege white, Western traditions by treating them as normal' (Bradford 2007, p.84). Likewise, a dominant quest structure, which promotes the representation of child voice through the eco-warrior archetypal frame, subsequently invokes a concomitant displacement of indigenous voice in Allende's trilogy.

The author uses three magical realist strategies to promote indigenous cultures, but Western perspectives encoded within ecocritical frames tend to disrupt the impact of Allende's narrative devices. Each protagonist acquires a capacity to transform into totemic creatures - Alexander becomes 'Jaguar' and Nadia becomes 'Eagle' - and their initiation into tribal ways promotes the blurred boundaries which confuse perceptual interpretations of magical events. Despite the promotion of alternate views of reality, these depictions of eco-warrior agency reinstate the victim stance of tribal people to such an extent that the superiority of Western epistemologies becomes evident when Jaguar and Eagle gain efficacy within the magical realms of indigenous power. Magical realist discourse promotes the phenomenal world in that uncanny events become anchored in mimetic detail (Faris 2004, p.14). Because these frames promote the ontological structures of indigenous peoples and their epistemological concepts of magical power the author's concern for indigenous representation seems unquestionable. But magical resolutions to complex environmental justice issues tend 
to limit authentic constructions of resistance in these novels. Western reliance upon technology, greed for natural resources or cultural artefacts, and the tendency to dominate nature through destructive practices are realistic factors by which Allende establishes mimetic detail. Nonetheless, fantastic quest resolutions that depict the valiant success of child protagonists, namely the magical ability to defeat overwhelming forces of evil, usurp discourse space and diminish the agential representations of indigenous tribes. These fantasy elements effectively distance the reader from the mimetic elements of Allende's text.

A third magical realist strategy centres upon ways of perceiving, in that indigenous practices are promoted as ecologically connected and therefore superior to the disconnectedness that defines Western characters in each novel. This distinction has been further depicted in characterizations of Western attitudes or environmental practices which disregard the value of wilderness areas and indigenous culture. Alternate ways of perceiving the natural world are portrayed by contrasting views of the Amazonian wilderness in Allende's first novel. The author contests anthropocentric approaches to the environment by promoting ecological awareness. As noted by Bradford, Mallan, Stephens \& McCallum (2008, p.99), City of the Beasts 'draws on an ecologically informed position which has affinities with deep ecology: intrinsic value is ascribed to all living things, and human beings are not attributed with any kind of privileged status'. This affirmation of connectedness within natural environments is closely linked with depictions of minority cultures in all three novels. Allende's initial affirmation - that of inherent value in indigenous cultures - provides an ecocritical frame that is extended by environmental justice issues in the following two novels of the series. The author asserts the value of connection with the natural environment as a desirable aspect of civilized culture. In Kingdom of the Dragon this assertion is depicted as a spiritual characteristic which is frequently absent from Western cultures. Allende's estimation of indigenous cultures has been established in a manner that contests anthropocentric beliefs in all three quest novels. But the promotion of the eco-warrior subject introduces acts of appropriation which have a potential to displace representations of agency. Allende's successful promotion of child voice and initiation into tribal magic invokes transference of power which, even as her protagonists gain tribal knowledge that supplements their newly formed magical powers, demonstrates discourse displacement in the lesser representation of indigenous tribes.

Because the alignment between indigenous perspectives and enviro-cultural preservation is consistently affirmed in Allende's three novels, anthropocentric views of the natural environmental are undermined. Instead, the author encodes elements of ecocriticism within each narrative in order to inform her readers of the moral values in acts of conservation and protectionism by which the aims of environmental justice movements may be achieved. In City of the Beasts, ecocritical views are occasionally aligned with a critical indigenous perspective: for example, as the Shaman, Walimai, attempts to explain Western ways to the secluded tribe, The People of the Mist:

The nahab [strange foreigners] are so crazed that they try to take with them the stones of the earth, the sand of the rivers, and the trees of the forest. Some want the earth itself. We tell them that the jungle cannot be carried away on their backs like a dead tapir, but they do not listen.

(Allende 2003, p.222).

The above excerpt asserts Walimai's perception that value derives from natural systems of stone, sand and trees, whilst these concrete elements, extracted from their natural state for strange purposes, are displaced from their intended environment. This view depicts the alienation of Western perspectives from indigenous ecological frames. Although conceptualisations of value held by Western cultures are challenged here by the perspectives of less dominant cultures, readers will also be aware of the uses for natural resources described within the text. The author uses this awareness to posit a test for Alexander: the discovery of precious stones during a quest into the tepui to find 'waters of healing' presents a choice that gives evidence of honourable character. Allende stages the forced choice scenario as a demonstration of the environmental dilemmas that inform her ecocritical frame: both water and precious minerals are aspects of the natural world, but the choices about their use require restraint and an assessment of need. 
These representations of the consequences of environmental and cultural abuse construct ideological confluence between magical realist ideologies and ecocritical frames. Each narrative establishes a strong narrator presence $-\mathrm{a}$ dominant representative voice - which speaks from the margins to educate and inform readers, to privilege minority culture, and finally to give voice to other ways of perceiving the world. Nonetheless, while the evident environmental justice themes that are depicted in each quest affirm indigenous voices, adolescent quest structures encode representations of agency that centre narrative development in the magical empowerment of child/adolescent protagonists: tribal people are frequently represented by non-indigenous perceptions, indigenous voices tend to be subdued, and agential frames, though well intentioned, may silence the subaltern voice. In such instances, representations of dependence inscribe a reliance on eco-warrior representations, or alternatively, may depict the eco-warrior subject as catalyst in restoring justice to marginalised tribes. These dependencies are problematic to the grounding ethic of both magical realist and environmental justice strategies.

In the rite of passage narrative, City of the Beasts, the voices of Allende's two protagonists are prominently established. Other than the perspective of Walimai, tribal voices are rarely represented in this novel. Similar dilemmas of representation occur in Forest of the Pygmies where the Pygmy tribe has quite limited representation in the occasional voiced opinion of a minor character, Bedé Dokou, and indigenous perspectives are somewhat absent until Nana-Asante is introduced as the novel establishes a concluding resolution. Nana-Asante, a shaman and healer, is depicted as a powerful magician, but is powerless to intervene and save her people from slavery until the two child protagonists connect with her in a secluded magical space, the 'Forest of the Spirits'.

Although Allende's environmental justice frame in Kingdom of the Golden Dragon depicts the ecologically diverse nature of the kingdom as a primary reason for the International Geographic Team's visit, narrative action centres upon the preservation of an artefact of magical power. In concluding scenes, even though the character of Prince Dil Bahadur is depicted as agential, dominant quest events that focus upon a rollicking adventure story tend to limit the impact of indigenous voice. The protection of the valued artefact, thought to be a golden dragon statue (the ancient voice of an oracle which speaks in the language of the Yeti and can be heard only by the kingdom's ruler), is represented as paramount to the welfare of the kingdom. Because of its unassuming appearance and linguistic properties, the Golden Dragon stone and its magical capacities remain a mystery, safe from criminal intent. The security of the natural ecology is, however, less assured. In concluding scenes while the King lies mortally wounded, the ancient stone oracle predicts the demise of the monarchy even as it affirms Dil Bahadur as leader of the Kingdom during a time of change. The character of the prince then establishes the voice of indigenous culture in this novel, but this representation is limited because efficacy is aligned with royalty and sourced by magical powers of the fantastic realm.

Within the three quests representations of agency have been informed by the voices most associated with representations undertaken on behalf of indigenous peoples rather than in more direct textual representations of minority perspectives. This problematic representation occurs because each novel depicts quest events that are frequently dominated by magical interventions. Powerful eco-warrior transformations intercede in a manner that similarly informs quest resolutions involving complex environmental justice issues. Consistently Allende identifies foreign influence as an environmental justice issue and depicts freedom from victimisation as a right of indigenous cultures. Within this interrogative frame representative voice seems an important consideration.

The ideological convergence of magical realism and ecocriticism in children's fiction results in other significant problems in eco-warrior representation. Huggan (2004), in an analysis of an increasing alignment between postcolonial theory and ecocriticism, notes that dislocation of agential capacities may be underestimated, and that romanticised views of subaltern cultures may serve to limit the development of agential capacities. He further suggests that an outcome of the dichotomy between representations of rationalism and emotionalism that is evidenced in the ideological convergence of ecocriticism 
and postcolonialism may be portrayed in the notion that indigenous peoples, animals, and natural resources must be preserved, protected or conserved (Huggan 2004, pp.701-733). This notion of the romancing of tribal seclusion suggests that principles of deep ecology depicted in Allende's novels may create an ideological frame of protection and conservation that does little to empower marginalised peoples. The author's promotion of deep ecology, a concept of existential equality that is most prominently argued in representations of Alexander's negotiation of tribal knowledge in City of the Beasts, may be first observed in his initiation into the tribal community through ceremonial ritual, but his awareness that tribal knowledge is linked with aspects of place which the tribes conserve is represented as an awakening. The secret places of the tepui secure indigenous knowledge in a symbiotic relationship between the People of the Mist and the colony of legendary beasts. Alexander's respect for these understandings of place and connection is represented as an alignment of tribal environments with sacred space because the magical beasts of the tepui represent repositories of tribal history. But this investment in secrecy depicts few possibilities for future tribal agency and restricts indigenous people to the conservation agenda.

A further problem is that a fantastic grounding of ecopolitical advocacy may subvert the thematic focus of the text. When child subjects, educated through rite of passage in the ways of tribal magic, may act within a situation whilst tribal peoples must wait for their own rescue, there is an inference that a form of neo-colonialism corroborates the eco-warrior role in each narrative frame. Forest of the Pygmies depicts neo-colonial aspects most prominently because marginalised groups are deprived of voice and agency while eco-warrior protagonists paradoxically experience magical powers. Alexander and Nadia engage in heroic interventions throughout the series but their capacity to act inscribes eco-warrior interventions through a magical lens. Magical intrusions establish individual power through totemic identification - Alexander as Jaguar; Nadia as Eagle. Once established in the first novel, this magical ability to transform is activated and is instrumental in the rescue of indigenous characters throughout the series. These intrusions frequently become ensconced within an enclosed otherworld - a space identifiably magical that inscribes a fantasy mode.

The creation of a secondary world that encodes agency in magical forms of empowerment signifies elements of fantasy that displace mimetic frames. In Allende's narratives this transition means that aspects of magical realism, which have been grounded in realistic detail, are susceptible to subversion. Fantasy has been activated in these magical segments and is best identified here as an interrogative mode. What Rosemary Jackson has discerned as fantasy's capacity for subversion becomes evident in the mode's avoidance of mimetic definition:

\section{A characteristic most frequently associated with literary fantasy has been the obdurate refusal of prevailing definitions of the real or possible [...]}

A fantasy is a story based on and controlled by an overt violation of what is generally accepted as a possibility... such violation of dominant assumptions threatens to subvert rules and conventions taken to be normative.

(Jackson 1981, p.14).

One such magical enclosure to be interpreted by a fantasy mode is El Dorado in City of the Beasts, the city where fabled beasts reside in safety and dialogue with members of the tribe. These magical spaces offer Alexander and Nadia an other-world space that defines a rite of passage by which the power to act on behalf of the tribes of the Amazon is affirmed. Magical elements that dominate this secondary world signal a mutation into fantasy at this point in the novel because readers are able to interpret the events as other than real.

Three narrative strategies give an indication that a fantasy mode is operative, namely, the use of enclosed spaces which assert the dominance of magical elements, the presence of a secondary world which operates in the absence of normal rules of existence, and finally a narrative point of view which affirms the fantastic through disconnection from mimetic representations. Textual slippage into a fantasy mode may be observed in Allende's depictions of enclosed and secret spaces where creatures of fable and fairytale are visible. In some instances the density of these fantastic elements indicates the presence of a 
secondary world that operates in the absence of normal rules of existence and thus reflects Jackson's definition. While the Yetis are depicted as real creatures in Kingdom of the Dragon, for example, their ghostly forms appear again in Forest of the Pygmies together with multitudes of spirit beings. These transformations are even more evident in the concluding scenes of Forest of the Pygmies: Mbembelé, the commandant, is attacked by a jaguar soon after Alexander transforms magically into his totemic form and this attack signals a disconnection from the grounding realism of magical realist texts. Allende incorporates a bricolage of magical elements derived from all three texts to establish fantastic representations of magical powers. In the following passage indigenous tribes are confronted by the magician Sombe and he, in turn, is confronted by an overwhelmingly magical force:

Just when the sorcerer [...] was emerging from the bonfire where flames had been licking his legs miraculously without burning him - a large white bird appeared in the south and circled the square several times. Alexander shouted with relief as he recognised Nadia.

The eagle had convoked forces that streamed into Ngoubé from the four cardinal points. The gorillas of the jungle led the parade [...]

Then came Queen Nana-Asante, glorious in the rags barely covering hernakedness, her white hair standing up like a halo of silver. [...]

Tensing was there, the Llama from the Himalayas who had answered Nadia's call in his astral body, along with his band of fearsome Yetis in war attire.

Walimai and the delicate spirit of his wife had brought thirteen fabled mythological beasts with them from the Amazon.

[...] And finally into the village trooped the vast shining throng of the jungle: the ancestors, and spirits of animals and plants, thousands and thousands of souls lit up the village with the sun of midday and cooled the air with a clean fresh breeze.

[...] The sorcerer was reduced to his true size. (Allende 2005, pp.284-285).
Increasingly magical signifiers both intensify and dominate the text at this crisis point in the novel. In effect, a secondary world overlays the previous magical realist representations and asserts elements of fantasy that resolve indigenous issues even as the sorcerer's power of illusion is reduced by the action of eco-warrior Nadia, appearing in totemic form as Eagle: 'The eagle had convoked forces that streamed into Ngoubé...' (Allende 2005, p.284)._Because thematic frames also centre upon environmental justice issues, this intrusion of the fantasy mode affirms magical elements and has the potential to disrupt authorial connections between magical realist and eco-critical perspectives. Writers of Magical Realist fictions centre the mode's interrogative intention upon perceptions of reality in the use of 'irreducible elements of magic' (Faris 2004, p.8). Because the postcolonial heritage of these fictions privileges subaltern views and particularly contrasts their alternate perceptions of reality with the dominant frame of Western rationalism, most authors use this focus to depict diverse cultural perspectives in the fused spaces of magical realist novels.

Whilst the magical realist mode sustains a capacity to interrogate point of view in ways that privilege minority or marginal perspectives in each of Allende's three novels, the magical interventions of eco-warriors who are themselves external to the culture remain dominant both as representative voices and also as sources of magical power. It is significant therefore that the tribal magic by which Alexander and Nadia are transformed into their totemic counterparts, Jaguar and Eagle, is the same magic that fails to deliver agential capacities to the indigenous cultures for which the eco-warriors intervene. Because the agential capacities of both protagonists are inscribed within the realm of fantasy this frame of power is a mutation which disrupts the magical realist reliance upon mimesis and exposes a problematic subversion of the significance of Allende's environmental justice themes. Magical resolutions to complex indigenous issues may significantly minimize the efficacy of environmental justice interventions encoded withinAllende's mimetic settings, but the most unfortunate aspect of Allende's eco-warrior depictions is the relative silence of indigenous voice. Although the eco-warrior protagonists and their concomitant quests for environmental 
justice promote a structural frame that celebrates child voice and agency; nonetheless, when aligned with the fantasy mode, the eco-warrior profile dominates each quest in a manner that subverts the effective depiction of agential capacities among indigenous tribes.

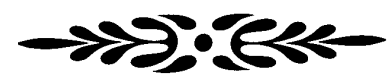

\section{REFERENCES}

Allende, I. (2002) City of the Beasts. Trans. Margaret Sayers Peden. London, Harper Collins Publishers

(2004) Kingdom of the Golden Dragon. Trans. Margaret Sayers Peden. London, Harper Collins Publishers.

(2005) Forest of the Pygmies. Trans. Margaret Sayers Peden. London, Harper Collins Publishers.

Bradford, C. (2007) Unsettling Narratives: Postcolonial readings of children's literature. Wilfred Laurier University, CA, Wilfred Laurier University Press.

Bradford, Mallan, Stephens \& McCallum (2008) New World Orders in Contemporary Children's Literature: Utopian transformations. Houndsmill, Palgrave Macmillan.

Campbell, J. (1949) Hero with a Thousand Faces. London, Fontana Press (1993).
D’haen, T. (1995) 'Magical realism and postmodernism: Decentering privileged centers', in L. Parkinson Zamora \& W. B. Faris (eds) Magical Realism: Theory, History, Community. Durham, Duke University Press.

Faris, W. (2004) Ordinary enchantments: Magical realism and the remystification of narrative. Nashville, Vanderbilt University Press.

Huggan, G. (2004) 'Greening’ postcolonialism: Eco-critical perspectives. $M F S$ 50, 3:701-733.

Jackson, R. (1981) Fantasy: The literature of subversion. London, Metheun.

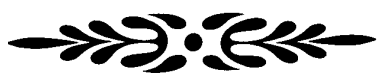

\section{BIOGRAPHICAL NOTE}

Yvonne Hammer is a $\mathrm{PhD}$ candidate in the Department of English, Faculty of Arts at Macquarie University. Her thesis examines mythic structure and constructions of heroic subjectivity in contemporary quest fictions written for child and adolescent audiences. She also directs a program for gifted and talented students at St Paul's Grammar School, Penrith.

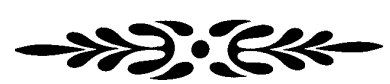

